\title{
Opposites attract: a case of magnet ingestion
}

\author{
Helen H.L. Wong, MD; Bruce A. Phillips, MD
}

\section{ABSTRACT}

Foreign-body ingestion is relatively common in the pediatric population and most objects pass through the gastrointestinal tract with minimal complications. Popular toy magnetic construction sets have resulted in numerous reports in the literature of serious complications including death following ingestion of multiple magnets. We report a case of a 5-yearold girl who presented to our emergency department with nonbilious vomiting and mild abdominal pain after accidentally ingesting 2 magnets 10 hours apart. Abdominal radiography showed the presence of 2 magnets, and a laparoscopy revealed multiple areas of bowel wall necrosis and perforation requiring subsequent laparotomy for repair of the bowel wall and retrieval of the magnets. This report aims to alert emergency care physicians of the necessity for early surgical referral with any multiple magnet ingestion to prevent severe complications.

$\overline{\text { Keywords: magnet ingestion, foreign-body ingestion, bowel }}$ perforation

\section{RÉSUMÉ}

L'ingestion de corps étrangers est relativement fréquente chez les enfants, et la plupart des objets ingérés passent spontanément dans le tractus digestif avec peu de complications. Les jouets de construction aimantés populaires ont fait l'objet, dans la littérature, de nombreux rapports sur des complications graves, y compris la mort après l'ingestion de plusieurs aimants. Nous présentons le cas d'une fillette de 5 ans qui est arrivée à notre service d'urgence avec des symptômes de vomissements non bilieux et de légères douleurs abdominales après l'ingestion accidentelle de 2 aimants à 10 heures d'intervalle. Une radiographie abdominale a révélé la présence des 2 aimants, et une laparoscopie a mis en évidence de multiples nécroses et perforations de la paroi intestinale. II a fallu pratiquer une laparotomie pour réparer la paroi intestinale et récupérer les aimants. Ce rapport a pour objet d'alerter les médecins d'urgence sur l'importance de diriger rapidement les cas d'ingestion de multiples aimants vers un chirurgien afin de prévenir de graves complications.

\section{INTRODUCTION}

Foreign-body ingestion is common among infants and children, although the majority do not cause serious morbidity. ${ }^{1,2}$ Less than $1 \%$ of ingested foreign bodies require surgical intervention. ${ }^{3}$ However, multiple magnet ingestion carries inherent risks that must be recognized by practitioners. Patients may present with minimal nonspecific symptoms, but require early surgical intervention to prevent significant morbidity.

\section{CASE REPORT}

A 5-year-old developmentally normal girl presented to the emergency department with a 2-day history of nonbilious vomiting and vague abdominal pain. She had no infectious contacts and had been afebrile. Her mother reported a reduction in her appetite, but she was drinking well and had a normal stool the day before. She had admitted to swallowing 2 magnets 10 hours apart. Her symptoms began 12 hours after the second magnet was ingested. She continued to have symptoms over the ensuing 2 days and was therefore brought in for an assessment.

Vital signs were all within normal limits and the child appeared to be in no distress; she was interactive and appropriately answered questions. Physical examination was unremarkable with the exception of deep tenderness and a slight fullness in the right lower quadrant. There were no peritoneal signs.

Abdominal radiography showed the presence of 2 magnets attached end to end in the right lower quadrant (Fig. 1). Shortly after a surgical consultation, the patient was taken to the operating room for exploratory laparoscopy. This revealed 3 bowel perforations and 5 near perforations in the small bowel requiring a subsequent laparotomy for repair and retrieval of the magnets. The

Emergency Department, British Columbia Children's Hospital, Vancouver, BC

Submitted Aug. 29, 2008; Revised Mar. 12, 2009; Accepted Mar. 15, 2009

This article has been peer reviewed.

CJEM 2009;11(5):493-5 
perforation sites were in the ileum and at the base of the appendix (Fig. 2). The 2 magnets were removed through one of the perforations (Fig. 3). Her postoperative period was unremarkable and she was discharged home 4 days after the surgery tolerating a full diet.

\section{DISCUSSION}

Although most foreign bodies that are ingested pass

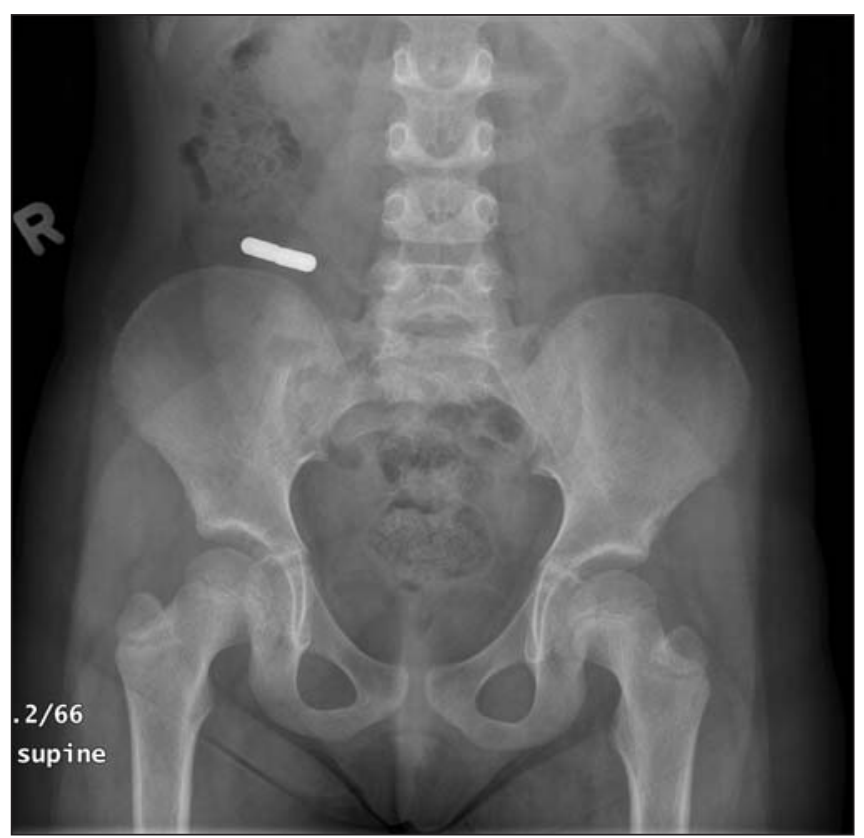

Fig. 1. Abdominal radiograph showing 2 magnets attached end to end in the lower right quadrant.

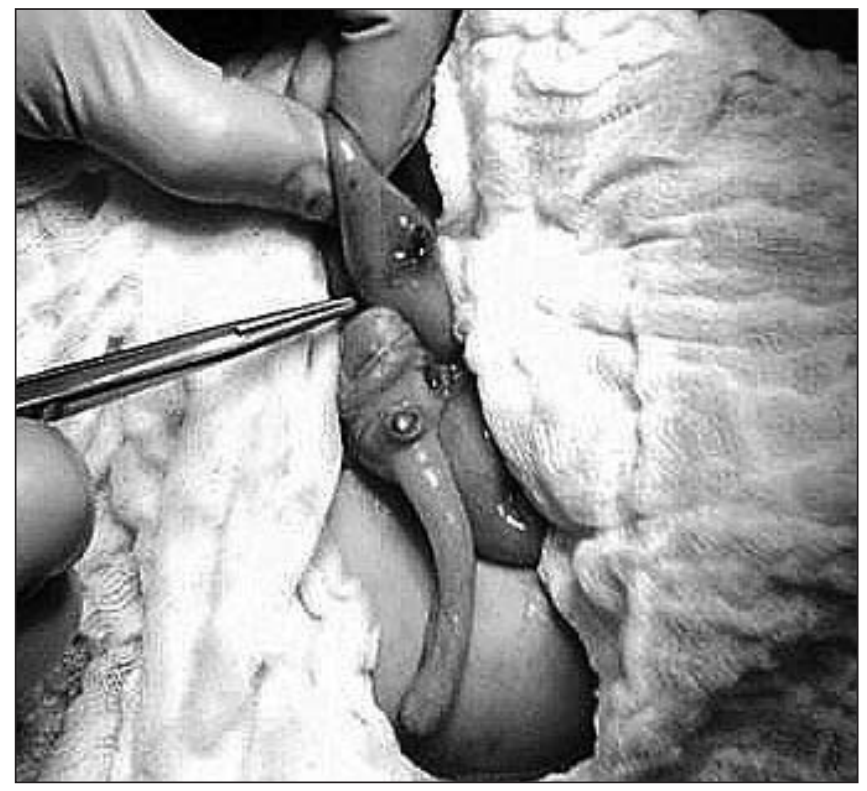

Fig. 2. Intraoperative photo showing 1 perforation in the ileum and 1 near perforation at the base of the appendix. without complications, a history of possible magnet ingestion should be treated more cautiously. Likely due to the popularity of magnetic toy sets, there have been numerous case reports in the last 5 years of serious complications including 1 death from the ingestion of multiple magnets. Complications occur when magnets in different bowel loops attract each other and trap bowel wall tissue between opposed surfaces. This can lead to bowel necrosis, perforation, volvulus and sepsis. ${ }^{47}$ In reviewing the previous case reports, which all required surgical intervention, ${ }^{4-7}$ it is not clear how often cases of multiple magnet ingestions require no intervention. We were unable to find any cases of these reported in the literature. However, the number of case reports documenting severe complications from single battery ingestion suggests that morbidity is not uncommon.

Since 2006, there have been numerous recalls from Canadian and US consumer product safety commissions to remove toys containing small magnets that could be ingested. We feel that banning the sale of such toys to children may prevent future increases in the incidence of cases. There is a need for emergency physicians to inquire about the possibility of magnet ingestion and be aware of the complications. Children with small necrotic perforations may have minimal symptoms as illustrated in this case. If the patient presents early enough, endoscopic removal may be possible. In our case, the child began having symptoms 12 hours following ingestion of the second magnet. The symptoms persisted but had not progressed. The timing of complications after ingestion is not clear, but likely depends on several factors including the strength of magnets, the number of magnets ingested and the timing of the ingestions.

In cases of suspected magnet ingestion, plain film radiography is a reasonable screening tool, as magnets are radio-opaque. If ingestion of a single magnet is

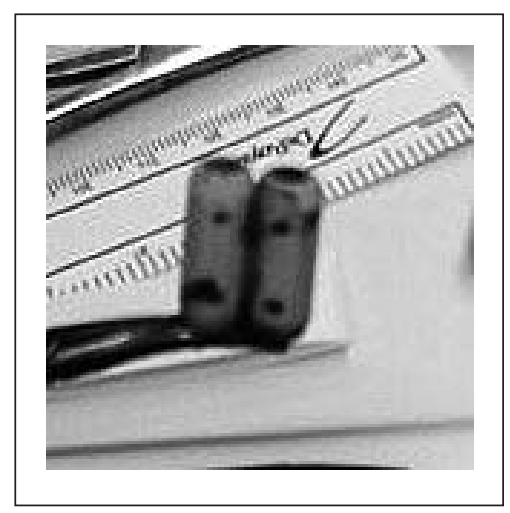

Fig. 3. Two magnets retrieved through one of the perforations. 
reported through the history, the physical examination is benign and there are confirmatory radiographs of only 1 magnet, then the patient may be followed by serial physical examinations until the magnet is expelled. We would recommend either an additional upright or lateral decubitus film to screen for signs of bowel perforation. However, the absence of free air does not exclude small perforations. The additional view was missed in our case, but the child was taken to the operating room emergently, which identified the multiple perforations.

Hypothetically, a single magnet may be attracted to other metallic objects either swallowed or in contact with the anterior abdominal wall. The patient should be counselled not to wear clothing with metallic buttons or buckles that overlay the abdomen for prolonged periods of time until the magnet is passed through the gastrointestinal system. Patients with mild symptoms of multiple

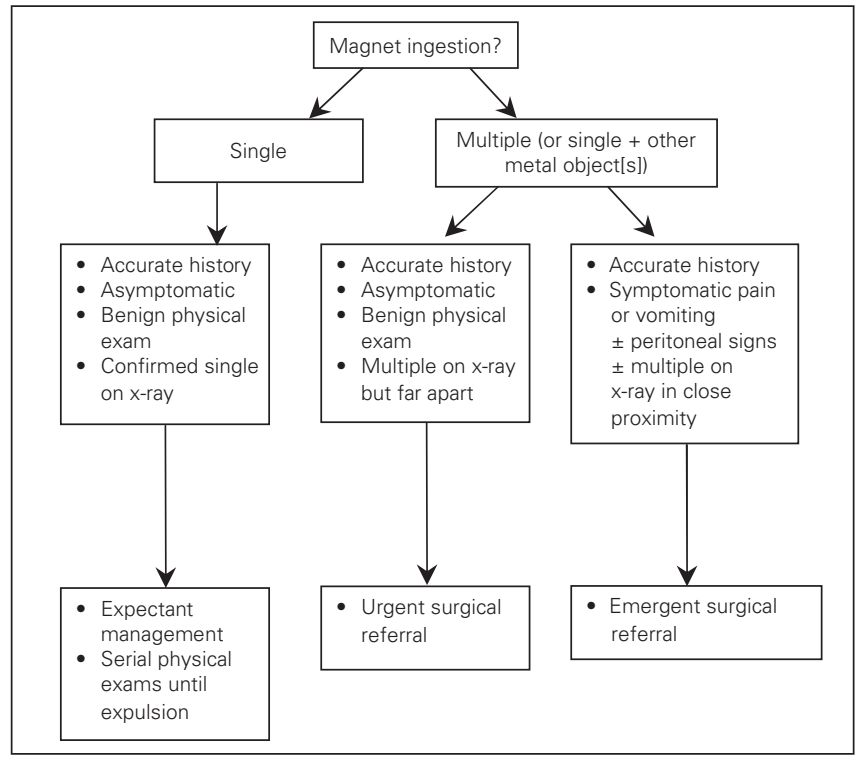

Fig. 4. Algorithm for suspected magnet ingestion. magnet ingestion should be referred urgently to the surgical service for consideration of removal, and should be referred emergently if symptoms of vomiting, abdominal pain or peritoneal signs are present (Fig. 4).

\section{CONCLUSION}

Foreign-body ingestion in the pediatric population is relatively common and most cases are treated conservatively. However, this case illustrates the danger of multiple magnet ingestion and the need for aggressive treatment with early surgical intervention to prevent morbidity.

Competing interests: None declared.

\section{REFERENCES}

1. Kay M, Wyllie R. Pediatric foreign bodies and their management. Curr Gastroenterol Rep 2005;7:212-8.

2. Uyemura MC. Foreign body ingestion. Am Fam Physician 2005;72:287-91.

3. Butterworth J, Feltis B. Toy magnet ingestion in children: revising the algorithm. J Pediatr Surg 2007;42:E3-5.

4. Centers for Disease Control and Prevention. Gastrointestinal injuries from magnet ingestion in children: United States 2004-2006. MMWR Morb Mortal Wkly Rep 2006;55:1296-300.

5. Dutta S, Barzin A. Multiple magnet ingestion as a source of severe gastrointestinal complications requiring surgical intervention. Arch Pediatr Adolesc Med 2008;162:123-5.

6. Hernandez Anselmi E, Gutlerrez San Roman C, Barrios Fontoba JE, et al. Intestinal perforation caused by magnetic toys. 7 Pediatr Surg 2007;42:E13-6.

7. Haraguchi M, Matsuo S, Tokail H, et al. Surgical intervention for the ingestion of multiple magnets by children. 7 Clin Gastroenterol 2004;38:915-6.

Correspondence to: Dr. Bruce Phillips, Emergency Department, British Columbia Children's Hospital, 4480 Oak St., Vancouver BC V6H 3V4; bphillips@cw.bc.ca 